\title{
A Novel Wind Energy Conversion System with Storage for Spillage Recovery
}

\author{
J. Cheng*, F. Choobineh \\ Department of Electrical and Computer Engineering, University of Nebraska-Lincoln, Lincoln, USA \\ Email: ${ }^{*}$ chengjiecc@huskers.unl.edu
}

Received 7 May 2015; accepted 10 July 2015; published 17 July 2015

\begin{abstract}
This paper proposes a new system configuration for integrating a compressed air energy storage system with a conventional wind turbine. The proposed system recycles the mechanical spillage of blades and stores it for later electricity generation with assistance from a rotary vane machine. The configuration and operational policy is explained, and a comparative case study shows that the proposed system recovers investment costs through savings on electricity procurement and revenue through power export.
\end{abstract}

Keywords

Wind Energy Conversion System, Compressed Air Energy Storage, Rotary Vane Machine

\section{Introduction}

The use of renewable energy technologies is receiving additional attention by power system planners and regulators. Renewable energy sources, such as wind and solar, are considered to be promising and sustainable solutions for the future energy needs. Among the renewable sources, wind energy has been the fastest-growing source of electricity in the world [1]. Its ubiquitous availability, environmental friendliness, and strong output make it a competitive energy resource compared to traditional resources.

A variety of wind turbines (WTs) have been designed and installed in wind farms for converting wind power to electricity. Most turbine designs rely on the traditional wind power profile, as shown in Figure 1, mapping various wind speeds to the output power. As can be seen, the domain is divided into four regions. In Region I, the power output pegs at zero because of low wind speed. In Region II, output power increases with a cube of the wind speed until generation capacity of turbine is reached. In Region III, as wind speed reaches and surpasses the rated speed, the WT keeps output power constant, while excessive energy in the wind is trimmed away by blade pitching. In Region IV, the output goes down to zero because wind speed is too high for the turbine to survive while operating.

However, a careful scrutiny of the power curve reveals that, in Region II, a WT is unable to utilize its full electrical capacity because of low wind speed, while in Region III, a great amount of wind energy is trimmed away because of the power limitation of the turbine generator, causing mechanical spillage. A mechanical spil-

*Corresponding author.

How to cite this paper: Cheng, J. and Choobineh, F. (2015) A Novel Wind Energy Conversion System with Storage for Spillage Recovery. Journal of Power and Energy Engineering, 3, 33-38. http://dx.doi.org/10.4236/jpee.2015.37006 


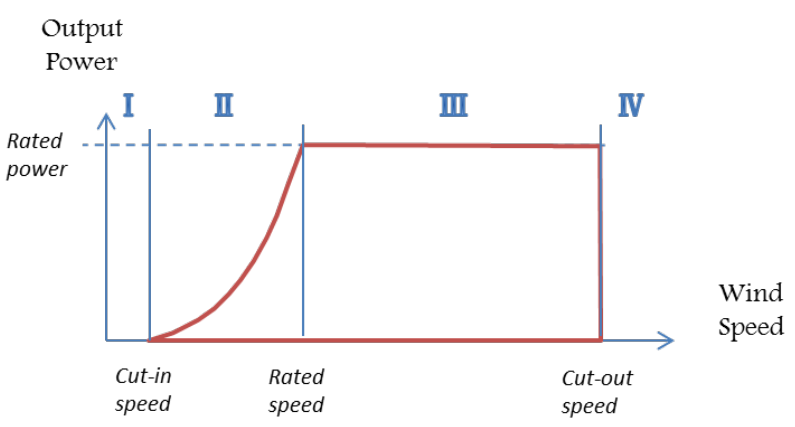

Figure 1. Traditional wind power profile.

lage is defined as the difference between potential power that blades can extract from the wind and the rated power of the generator. It should be noted that in the case of a grid-connected infinite bus system, although no electric spillage is present, mechanical spillage still exists.

Since we have identified the capacity vacancy in Region II and mechanical spillage in Region III, our idea is to recycle the mechanical spillage into storing and to regenerate electricity from the storage, therefore increasing overall wind power generation.

This paper is organized as follows. Section 2 describes the system configuration, operational procedures and evaluation metrics. Section 3 studies the performance of the system numerically. Finally, Section 4 draws conclusions.

\section{Configuration and Procedures}

A traditional WT generation system usually consists of blades, a gearbox, a generator, and some electronics. In the proposed design, the traditional speed-up gearbox is replaced by a differential planetary gearbox, shown in Figure 2. A differential planetary gearbox has one primary shaft to the left, and two coaxial secondary shafts to the right. The secondary shafts consist of a solid shaft to the generator and a hollow shaft to the Rotary Vane Machine (RVM). ARVM is coupled to the hollow shaft so as to regulate the power delivery between primary shaft and secondary shafts. A compressed air tank is linked to the RVM via a switching valve. The wind turbine is connected to the grid through a point of common coupling (PCC), forming a community-scale microgrid. The fundamentals of the structure and usage of each component will be discussed in the following subsections.

\subsection{Blade}

Blades are mechanical parts that are optimally designed to capture energy from the wind. According to the classic formula for a wind power curve, wind energy is the product of wind energy density, swept area of the blade, and the $C_{p}$ coefficient. The $C_{p}$ coefficient is the function of tip speed ratio and pitching angle [2]. For a real wind turbine system, the limit on the deliverable blade power is extrapolated by removing generator capacity constraints from the classic power curve and subtracting a mechanical loss.

\subsection{Differential Gearbox}

A differential gearbox is a gear system that enables uneven delivery of power from the primary shaft to two different secondary shafts. A planetary gearbox is one type of differential gearbox consisting of ring gear in the out layer, planetary gears in the middle, and sun gear in the center.

In the proposed application, shaft on the left-hand side is connected to the blade shaft; and the solid shaft on the right-hand side is connected to the generator. The hollow shaft on the right which links to the planetary gear set is connected to the RVM, providing positive or negative power to compensate for the difference between input and output, as desired. In steady state analysis, the contributive/input power and consumptive/output power have to match at all times.

\subsection{Rotary Vane Machine}

An RVM has an off-center shaft and spring-engaged vanes that jointly create a series of uneven chambers in its 


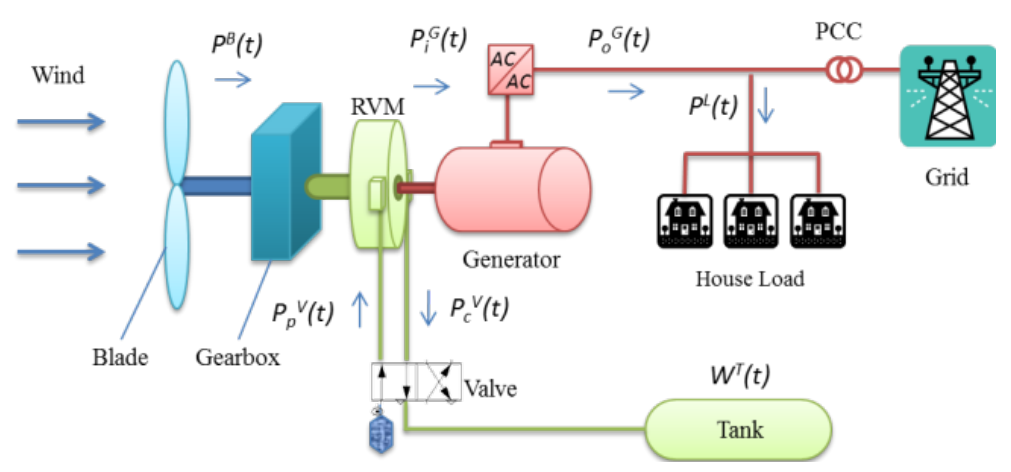

Figure 2. Proposed wind conversion system.

housing [3]. An RVM is incorporated into the system through a planetary gearbox to recapture power while wind power is in surplus, and to generate power while wind power is in deficit. The details of its two working modes are described below.

While the switching valve stays at the left-side position, as depicted in Figure 3(a), the inlet of the RVM is connected to atmosphere while the outlet is connected to the compressed air tank. The RVM is working in the compressor mode in which the vanes are driven by a shaft, compressing the air to its outlet. On the contrary, while the switching valve switches to the right-hand side position, as in Figure 3(b), the tank outlet air flow is reversed. The RVM works as an expander, in which the vanes are driven by compressed air, thereby exporting power.

\subsection{Air Tank Storage}

An air tank is used as a storage component, working jointly with the RVM. Each type of tank has its threshold of safety pressure. Thus, for a given volume and safety pressure, and a specified constant temperature, the maximum energy in a tank is determined. In this sense, the characteristics of compressed air storage are analogous to battery storage, where capacity can be expanded by simply parallelizing component units to constitute bulk storage.

\subsection{Control Policy}

An energy management policy is developed to maximize the benefit of energy production from the proposed system. The control logic is summarized in Figure 4.

The blade power is calculated based on the given wind speed. The difference between the blade power and the generator capacity becomes an indicator of the working status of the RVM. If the deviation is positive, the RVM is switched to compressor mode, in which the aforementioned mechanical spillage is recycled and stored in the form of compressed air. If the deviation is negative, RVM switches to expander state to supplement the power generation through the gearbox.

Through the operation procedure, it is assumed that the power output of both the generator and RVM cannot go beyond their capacity.

\subsection{Cost Model}

The total energy cost (EC) consists of two parts: 1) the facility costs, consisting of the initial investment cost and annual operation and maintenance ( $\mathrm{O} \& \mathrm{M}$ ) cost and 2) the procurement costs, the net cost of buying electricity from the grid, minus selling electricity to the grid. Those costs have to be converted into the same planning horizon $H$ through discount factors. Net metering policy is applied with a flat electricity rate within $H$.

\section{Performance Study of the System}

In order to illustrate the performance of the proposed system, a comparative case study is presented in this section. The following three cases will be studied: 


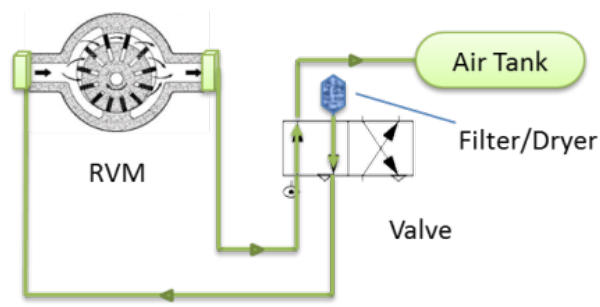

(a)

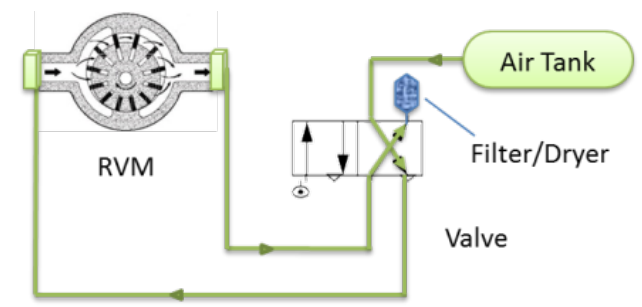

(b)

Figure 3. (a) RVM as a compressor and (b) RVM as an expander.

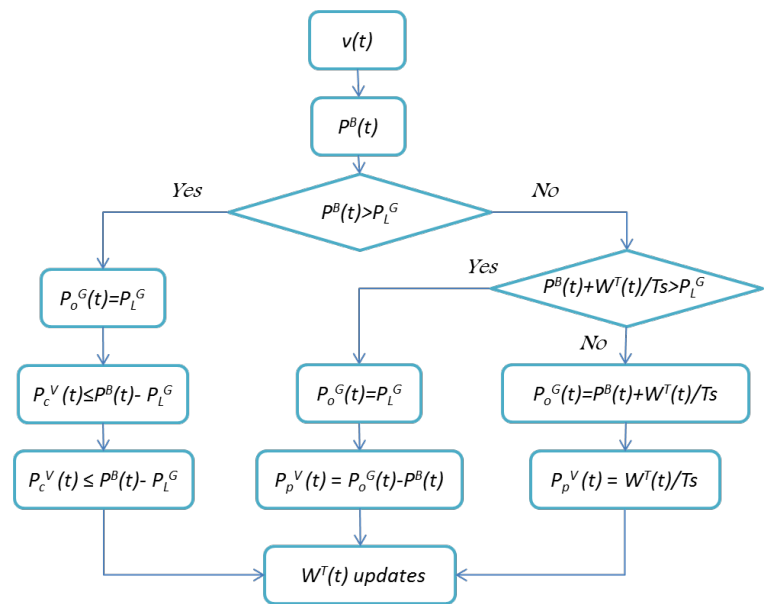

(a)

\begin{tabular}{|l|l|l|l|}
\hline$\underline{\text { Symbol }}$ & \multicolumn{1}{|c|}{ Description } & $\underline{\text { Symbol }}$ & \multicolumn{1}{|c|}{ Description } \\
\hline$v(t)$ & $\begin{array}{l}\text { Wind speed at time } \\
t\end{array}$ & $P_{c}{ }^{V}(t)$ & $\begin{array}{l}\text { Compression power } \\
\text { at time } t\end{array}$ \\
\hline$P^{B}(t)$ & $\begin{array}{l}\text { Blade power at } \\
\text { time } t\end{array}$ & $P_{p}^{V}(t)$ & $\begin{array}{l}\text { Expansion power at } \\
\text { time } t\end{array}$ \\
\hline$P_{i}{ }^{G}(t)$ & $\begin{array}{l}\text { Input power of } \\
\text { generator at time } t\end{array}$ & $P_{L}^{V}$ & $\begin{array}{l}\text { Rated output power } \\
\text { of RVM }\end{array}$ \\
\hline$P_{o}{ }^{G}(t)$ & $\begin{array}{l}\text { Output power of } \\
\text { generator at time } t\end{array}$ & $W^{T}(t)$ & $\begin{array}{l}\text { Energy in the tank at } \\
\text { time } t\end{array}$ \\
\hline$P_{L}{ }^{G}$ & $\begin{array}{l}\text { Rated power of } \\
\text { wind turbine }\end{array}$ & $W_{L}{ }^{T}$ & $\begin{array}{l}\text { Rated capacity of } \\
\text { tank storage }\end{array}$ \\
\hline
\end{tabular}

(b)

Figure 4. (a) Energy management flow chart and (b) Term discription.

- Case 1: A community without wind energy

- Case 2: A community with a single WT; and

- Case 3: A community with the proposed system

\subsection{Conditions and Parameters}

The planning horizon $H$ is set at 7 days, consisting of 168 one-hour time step. The hourly wind speed is retrieved from the historical data at Springview, Nebraska. And the hourly load demand was obtained from the NE-ISO power pool [4] that has been scaled down to the $0-400 \mathrm{~kW}$ range to simulate the consumption pattern of a small community.

The system component parameters are listed in Table 1. The annual interest rate is assumed to be $6 \%$. The electricity rate is constant at 3.6 cents/kWh. The economic life is 20 years for the WT, RVM, and tank, respectively.

\subsection{Results}

As shown in Figure 5(a), the total energy costs of the three cases are $\$ 1.813$, $\$ 1.807$, and $\$ 1.798$, respectively. This indicates a decreasing cost trend as one moves from Case 1 to Case 3. Moreover, the average power flow through the PCC is also reduced from the original $300 \mathrm{~kW}$ to $78 \mathrm{~kW}$ and $52 \mathrm{~kW}$, representing a $74 \%$ and $83 \%$ decrease, respectively. The aforementioned trend proves that the proposed system not only reduces the kWh cost but also reduces the power flow through the PCC. This indicates microgridself-sufficiency improves as one moves from Case 2 to Case 3.

The proposed system is designed to increase the capacity factor. Figure 5(b) shows that the capacity factor has been improved by $8.4 \%$, from $86.8 \%$ to $95.2 \%$, providing additional electricity generation of $3.829 \mathrm{kWh}$ during period $H$.

The detail of the hourly generation is presented in Figure 6. As it can be seen, the proposed system gives full 


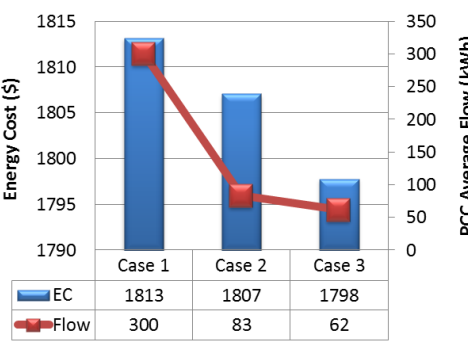

(a)

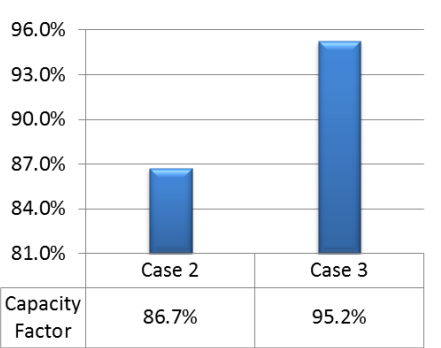

(b)

Figure 5. (a) Comparison of energy cost and PCC flow and (b) Comparison of capacity factor.

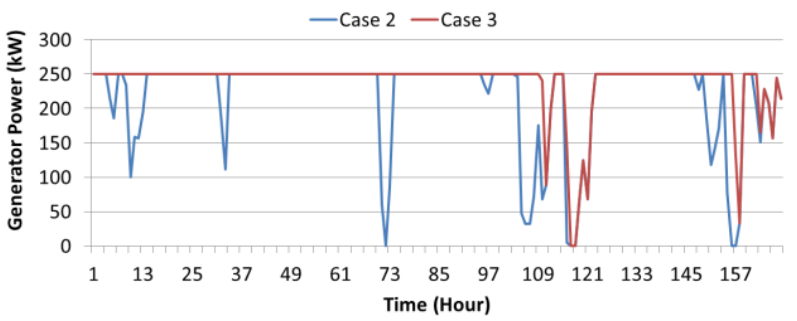

Figure 6. Comparison of generation.

Table 1. Component parameters.

\begin{tabular}{cccccc}
\hline Symbol & Description & Value & Symbol & Description & Value \\
\hline$P_{L}^{G}$ & Rated power of WT & $250 \mathrm{~kW}$ & $P_{L}^{V}$ & Rated power of RVM & $375 \mathrm{~kW}$ \\
$v^{\text {in }}$ & Cut-in wind speed & $2.5 \mathrm{~m} / \mathrm{s}$ & $W_{L}^{T}$ & Rated capacity of tank & $2000 \mathrm{kWh}$ \\
$v^{\text {rated }}$ & Rated wind speed & $6.0 \mathrm{~m} / \mathrm{s}$ & $\eta^{G}$ & Generator efficiency & $95 \%$ \\
$C_{p}$ & Coefficient of power & 0.39 & $\eta^{V_{c}}$ & Compression efficiency & $60 \%$ \\
$D$ & Blade diameter & $81.5 \mathrm{~m}$ & $\eta^{V_{p}}$ & Expansion efficiency & $70 \%$ \\
$f^{\text {loss }}$ & Friction loss & $19.5 \mathrm{~kW}$ & $\eta^{T}$ & Air tank efficiency & $95 \%$ \\
\hline
\end{tabular}

capacity generation within the first 109 hours, while Case 2 has several negative gaps (spikes) in its power supply. However, after $109^{\text {th }}$ hour, Case 3 also experiences strong fluctuation on its output, due to the lack of wind resource and depletion of tank storage.

The hourly operation of the RVM is shown in Figure 7. Its performance follows the pattern defined in the control policy. While wind is in surplus, the RVM is constantly running as a compressor to store energy as well as to compensate for tank leakage. While capacity vacancy appears, the RVM runs to support generation of electricity as long as enough pressure in the tank exists. The RVM stops running while wind is insufficient and storage is empty, creating the aforementioned negative output spikes in Figure 6.

The comparison, under the described circumstances, represents a tentative conclusion that the proposed system is able to recover the investment cost through the savings of electricity procurement as well as the sale of electricity exports.

\section{Conclusion}

This paper has proposed a novel WECS configuration that integrates a compressed air assisted storage system into a traditional WT system, recycling the mechanical spillage previously trimmed by the traditional wind power curve and regenerating electricity from storage as needed. Compared to a single WT or conventional CAES, the proposed system increases the capacity factor and, furthermore, the overall electricity generation. Therefore the proposed system renders an economic solution to fulfill energy demand of the community. 


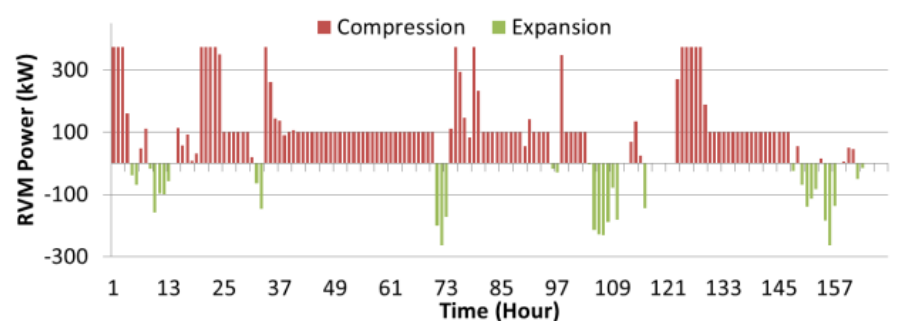

Figure 7. RVM performance.

\section{Acknowledgements}

The authors gratefully acknowledge the financial support by American Public Power Association (APPA) under Scholarship of Demonstration of Energy \& Efficiency Development (DEED): Compressed Air Assisted Wind Power Generation and Regulation (Student Research Grant number: CS-1087).

\section{References}

[1] Catalao, J.P.S., Pousinho, H.M.I. and Mendes, V.M.F. (2012) Optimal Offering Strategies for Wind Power Producers Considering Uncertainty and Risk. IEEE Systems Journal, 6, 270-277. http://dx.doi.org/10.1109/JSYST.2011.2163009

[2] Miller, N.W., Sanchez-Gasca, J.J., Price, W.W. and Delmerico, R.W. (2003) Dynamic Modeling of GE 1.5 and 3.6 MW Wind Turbine-Generators for Stability Simulations. 2003 IEEE Power Engineering Society General Meeting (IEEE Cat. No. 03CH37491).

[3] DOE Fundamentals Handbook: Mechanical Science. Volume 2. United States. http://energy.gov/sites/prod/files/2013/06/f2/h1018v2.pdf

[4] ISO New England, Energy, Load, and Demand Reports. http://www.iso-ne.com/isoexpress/ 